\title{
Clinical and functional characteristics of patients two years after being affected by the soybean asthma epidemic in Barcelona
}

Josefina Sabrià, Josep M Antó, Jordi Sunyer, Josep Roca, Ferran Morell, Robert Rodríguez-Roisín, María J Rodrigo, Rosa Codina

\begin{abstract}
Background-Patients affected during the asthma outbreaks caused by soybean dust inhalation in Barcelona presented with sudden onset of severe asthma followed by the rapid relief of symptoms after treatment. Two years after the epidemics ended, a case-control study was conducted in which the clinical, functional, and immunological characteristics of these asthma patients (a randomised sample of asthmatic patients admitted as emergency cases on epidemic days, $n=213$ ) were compared with those of a control group (a random sample of asthmatic patients admitted as emergency cases for attacks of asthma on non-epidemic days, $n=170$ ).

Methods - The study included the administration of the ATS-DLD78 standardised respiratory questionnaire, the measurement of atopy, and performance of spirometric tests and a methacholine inhalation test.
\end{abstract}

Results - Patients with epidemic asthma reported fewer symptoms of asthma, had attended emergency departments less frequently during the previous year for acute attacks of asthma, were taking fewer inhaled corticosteroids at the time of the study, and attended medical follow up less frequently than did the patients with nonepidemic asthma. However, the cases and controls showed no differences in ventilatory capacity or reactivity to the methacholine bronchoprovocation test.

Conclusions - Two years after the end of the soybean epidemics, people affected by epidemic asthma had a favourable prognosis. This finding contrasts with a higher risk of life threatening asthma and death during the epidemics. This paradox could be the result of a complex interaction between host and conditions of exposure.

(Thorax 1994;49:906-909)

The soybean dust-related outbreaks of epidemic asthma which occurred in Barcelona constitute one of the best examples of sudden severe asthma. ${ }^{1-5}$ Patients presenting with acute asthma during the outbreaks (between 1981 and 1987) characteristically showed a sudden onset of their attack, with a relatively high proportion of deaths and admissions to intensive care units. Most of these epidemic asthma attacks, however, were followed by the rapid relief of symptoms after conventional treatment in hospital emergency departments or intensive care units. ${ }^{6}$ Despite this clinical picture, soybean epidemic asthma could not be linked to specific clinical or functional characteristics of the patients.

The elimination of asthma epidemics, which coincided with the enforcement of dust control regulations at the silo in Barcelona harbour in $1987,{ }^{7}$ has enabled us to study subjects who suffered asthma in conditions which probably were similar to those before the onset of the epidemics. We considered whether there were any significant differences between the characteristics of the asthma in the patients in the epidemic and non-epidemic groups two years after the end of the outbreaks, and whether those affected during the epidemics had characteristics which made them generally more susceptible to acute severe asthma.

\section{Methods}

The study population was made up of patients over 14 years of age resident in Barcelona, who had been admitted to hospital emergency departments with an acute attack of asthma during the 1981-7 epidemics. Patients were selected from those registered in the "respiratory emergency room system of Barcelona" developed to investigate the asthma epidemics. ${ }^{8}$

Two groups of patients were selected: (1) a random sample of 213 asthma patients who were admitted to emergency departments during the last epidemic in September $1987(n=$ 93) or during the 26 epidemic days between 1981 and $1987(n=120)$, and (2) a random sample of 170 asthmatic patients who had not been in hospital on an epidemic day (nonepidemic asthma patients), but who had attended the hospital emergency departments during the three month period after the last epidemic.

The study was carried out two years after the epidemics ended and included the administration of the ATS-DLD78 standardised respiratory questionnaire ${ }^{9}$ with additional questions from IUATLD,${ }^{10}$ measurement of atopy and total serum IgE concentrations, baseline spirometric values, and methacholine challenge test. Atopy was assessed by standard skin prick testing to 16 common allergens which included house dust, Dermatophagoides pteronyssinus, $D$ pharinae, cat, horse, cow and dog danders, tree mix, graminaceae mix, weed mix, and mould 

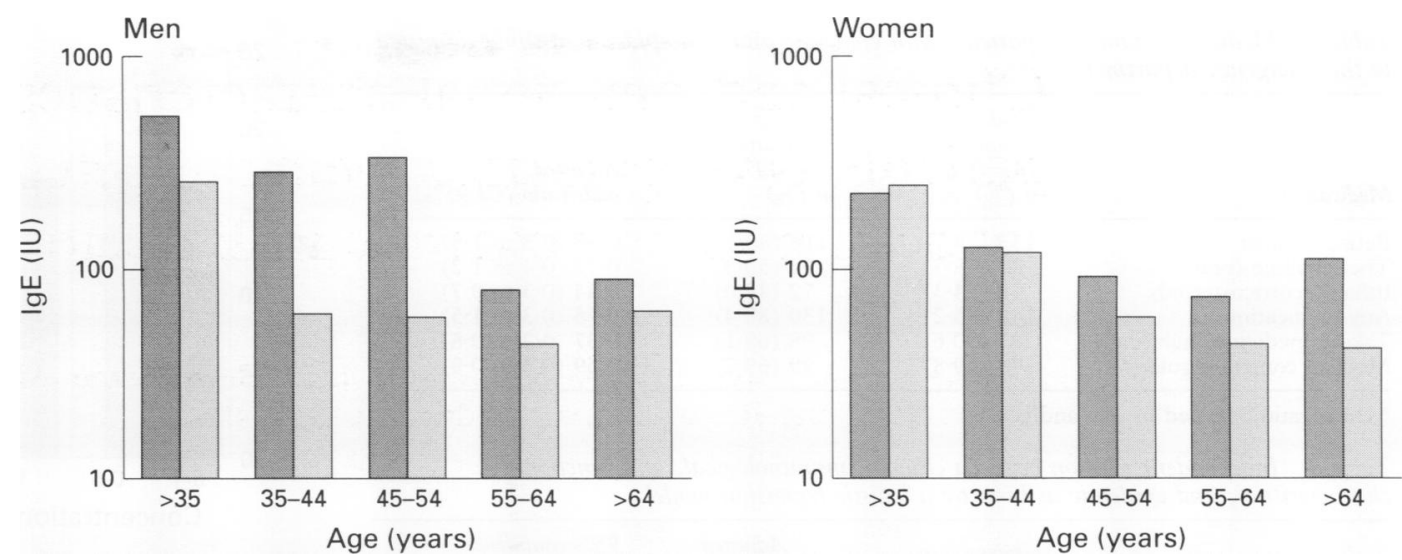

Figure 1 Geometric mean of total IgE in patients with epidemic (left hand columns) and non-epidemic asthma stratified by age and sex.

mix. A reaction was considered positive when a weal diameter $\geqslant 3 \mathrm{~mm}$ for one or more allergens was observed. Total serum IgE concentration was assessed using a paper radioimmunosorbent test (Pharmacia Diagnosis AB, Barcelona, Spain). Results were expressed in $\mathrm{IU} / \mathrm{ml}$.

Baseline spirometric tests were carried out with a Datospir-92 spirometer with the patient seated and wearing a noseclip. Percentage predicted values of forced expiratory volume in one second $\left(\mathrm{FEV}_{1}\right)$ and forced vital capacity (FVC) based on age, sex, and height in $\mathrm{cm}$ were calculated from the reference equations reported by Roca et al. ${ }^{11}$ After baseline measurements of pulmonary function, a methacholine challenge test was performed on patients with $\mathrm{FEV}_{1}>40 \%$ of predicted. After inhalation of nebulised distilled water, five deep breaths of the methacholine dose were administered using a Hudson nebuliser at four minute intervals. The following increasing con-

Table 1 Prevalence of respiratory symptoms during the last year in patients with epidemic and non-epidemic asthma admitted to the emergency department

\begin{tabular}{|c|c|c|c|}
\hline Symptoms & $\begin{array}{l}\text { Epidemic } \\
\text { asthmatics } \\
(n=169) \\
n(\%)\end{array}$ & $\begin{array}{l}\text { Non-epidemic } \\
\text { asthmatics } \\
(n=147) \\
n(\%)\end{array}$ & Odds ratio (CI 95\%)* \\
\hline Wheeze & $116(68 \cdot 6)$ & $115(78 \cdot 2)$ & $0.60(0.3$ to $1 \cdot 1)$ \\
\hline Attacks of shortness of breath & $93(55 \cdot 0)$ & $87(59 \cdot 2)$ & $0.89(0.4$ to 1.7$)$ \\
\hline Tightness in the chest & $62(36 \cdot 7)$ & $79(53 \cdot 7)$ & $0.53(0.3$ to 0.8$)$ \\
\hline Woken up by attacks of cough & $56(33 \cdot 1)$ & $55(37 \cdot 4)$ & $0.85(0.5$ to 1.5$)$ \\
\hline \multirow{4}{*}{$\begin{array}{l}\text { Woken up by attacks of } \\
\text { shortness of breath } \\
\text { Attacks of asthma } \\
\text { Visits for asthma to } \\
\text { emergency department }\end{array}$} & & & \\
\hline & $\begin{array}{l}73(43 \cdot 2) \\
64(37 \cdot 9)\end{array}$ & $\begin{array}{l}69(46 \cdot 9) \\
73(49 \cdot 7)\end{array}$ & $0.87(0.5$ to 1.4$)$ \\
\hline & & & \\
\hline & $34(20 \cdot 1)$ & $54(36 \cdot 7)$ & $0.43(0.3$ to 0.7$)$ \\
\hline
\end{tabular}

* Odds ratio adjusted by age and sex. Additional adjustment for smoking did not change the magnitude or the statistical significance of these odds ratios.

Table 2 Results of skin prick testing to common allergens in patients with epidemic and non-epidemic asthma admitted to the emergency department

\begin{tabular}{|c|c|c|c|}
\hline Skin prick test & $\begin{array}{l}\text { Epidemic } \\
\text { asthmatics } \\
(n=159) \\
n(\%)\end{array}$ & $\begin{array}{l}\text { Non-epidemic } \\
\text { asthmatics } \\
(n=147) \\
n(\%)\end{array}$ & Odds ratio (CI 95\%)* \\
\hline Positive & $124(77 \cdot 9)$ & $87(63 \cdot 5)$ & $2.62(1.51$ to 4.53$)$ \\
\hline $1-3$ allergens & $46(28 \cdot 6)$ & $33(23 \cdot 5)$ & $2.91(1.51$ to 5.32$)$ \\
\hline $4-10$ allergens & $66(41 \cdot 7)$ & $44(32 \cdot 3)$ & $3.39(1.82$ to 6.71$)$ \\
\hline$>10$ allergens & $12(7 \cdot 6)$ & $10(7 \cdot 3)$ & $1.41(0.66$ to 3.74$)$ \\
\hline House dust & $72(45 \cdot 3)$ & $46(33 \cdot 1)$ & $1.19(0.95$ to 1.47$)$ \\
\hline Dermatophagoides pteronyssinus & $85(53.5)$ & $67(48 \cdot 2)$ & $1.12(0.98$ to 1.27$)$ \\
\hline Dermatophagoides pharinae & $83(52 \cdot 2)$ & $58(41 \cdot 7)$ & $1.13(0.99$ to 1.27$)$ \\
\hline Cat danders & $23(14 \cdot 6)$ & $22(15.9)$ & $0.98(0.91$ to 1.09$)$ \\
\hline Tree II & $25(15 \cdot 7)$ & $14(10 \cdot 1)$ & $1.23(0.94$ to 1.51$)$ \\
\hline Graminaceae & $32(20 \cdot 1)$ & $15(10.8)$ & $1.46(0.99$ to 2.01$)$ \\
\hline Weed mix & $38(23.9)$ & $18(12.9)$ & $1.38(0.98$ to 1.82$)$ \\
\hline
\end{tabular}

* Adjusted by age and sex. Odds ratio for skin test responsiveness to at least one allergen adjusted by age, sex, and smoking $=2.75(95 \% \mathrm{CI} 1.56$ to 4.82$)$. centrations of methacholine were used: $0 \cdot 1$, $0 \cdot 5,1,2,5,10$ and $25 \mathrm{mg} / \mathrm{ml}$. The test was stopped when a fall in $\mathrm{FEV}_{1}$ of $20 \%$ or more compared with the baseline $\mathrm{FEV}_{1}$ was recorded, or when the highest dose of methacholine had been administered. Subjects withheld their bronchodilator before spirometric testing. A bronchodilator test was carried out on subjects who did not perform the methacholine test.

\section{STATISTICAL ANALYSIS}

The $\chi^{2}$ test was used to determine whether the differences found between epidemic and nonepidemic asthmatic patients in the various qualitative variables were statistically significant. The Student's $t$ test was used for comparing normally distributed quantitative variables, and the non-parametric Mann-Whitney $U$ test for quantitative variables not normally distributed. The magnitude of the association between being an epidemic asthmatic patient and various qualitative variables was estimated by calculating the odds ratio. The $95 \%$ confidence intervals (CI) were calculated using the Cornfield method. Adjustment for age, sex and smoking history, as well as for other confounding variables, was carried out using logistic regression (EGRET statistical package).

\section{Results}

Of the 383 eligible individuals 316 were studied, comprising 169 patients with epidemic asthma (cases) and 147 non-epidemic asthma patients (controls). The rate of response of those alive and residing in Barcelona was $79 \cdot 1 \%$ and $86.5 \%$ for cases and controls, respectively. The proportion of men was $49 \cdot 1 \%$ and $37 \cdot 4 \%$, respectively $(p<0.05)$. The mean age of those affected by the epidemics was 52.3 years and that of the non-epidemic asthmatic patients was 46.9 years $(p<0.01)$.

Patients suffering epidemic asthma reported fewer symptoms during the preview year than non-epidemic subjects (table 1). These differences were statistically significant for "tightness in the chest" and "attacks of asthma". In addition, $20 \cdot 1 \%$ of patients with epidemic asthma had attended hospital emergency departments in the previous year compared with $36.7 \%$ of controls $(p<0.001)$. These differences were not 
Table 3 Medication taken by patients with epidemic and non-epidemic asthma admitted to the emergency department

\begin{tabular}{|c|c|c|c|}
\hline Medication & $\begin{array}{l}\text { Epidemic } \\
\text { asthmatics } \\
(n=169) \\
n(\%)\end{array}$ & $\begin{array}{l}\text { Non-epidemic } \\
\text { asthmatics } \\
(n=147) \\
n(\%)\end{array}$ & $\begin{array}{l}\text { Adjusted } \\
\text { odds ratio (CI 95\%)* }\end{array}$ \\
\hline Beta-2 agonist & $133(78 \cdot 7)$ & $118(80 \cdot 3)$ & $0.85(0.5$ to 1.5$)$ \\
\hline Theophylline (oral) & $82(48 \cdot 5)$ & $74(50 \cdot 3)$ & $0.72(0.4$ to $1 \cdot 2)$ \\
\hline Inhaled corticosteroids & $58(34 \cdot 3)$ & $72(49 \cdot 0)$ & $0.44(0.3$ to 0.7$)$ \\
\hline Any medication & $144(85 \cdot 2)$ & $130(88 \cdot 4)$ & $0.75(0.3$ to 1.5$)$ \\
\hline Taking medicines habitually & $83(50 \cdot 6)$ & $98(68 \cdot 1)$ & $0.37(0.2$ to 0.8$)$ \\
\hline Medical control regularly & $98(59 \cdot 8)$ & $99(69 \cdot 7)$ & $0.59(0.3$ to 0.9$)$ \\
\hline
\end{tabular}

* Odds ratio adjusted by age and sex.

Table 4 Independent relation between clinical, immunological, and functional characteristics, and epidemic asthma by a logistic regression model

\begin{tabular}{llll}
\hline Variable & Category & $\begin{array}{l}\text { Adjusted } \\
\text { odds ratio }\end{array}$ & $\begin{array}{l}95 \% \text { confidence } \\
\text { intervals }\end{array}$ \\
\hline $\begin{array}{l}\text { Attacks of shortness } \\
\text { of breath }\end{array}$ & $\begin{array}{l}\text { No } \\
\text { Yes }\end{array}$ & 1 & \\
Cutaneous reactivity & 0 & 0.24 & $(0.09$ to 0.60$)$ \\
Age (years) & $\geqslant 1$ & 1 & $(1.88$ to 6.35$)$ \\
& $<45$ & 3.45 & \\
Sex & $45-60$ & 1 & $(1.22$ to 4.28$)$ \\
Inhaled corticosteroids & $>60$ & 3.10 & $(1.41$ to $6 \cdot 80)$ \\
& Female & 1 & \\
Smoking habit & Male & 1.04 & $(0.56$ to $1 \cdot 71)$ \\
& No & 1 & \\
& Yes & 0.55 & $(0.32$ to 0.93$)$ \\
& Never smoker & 1 & $(1.03$ to 3.44$)$ \\
& Past smoker & 1.89 & $(0.93$ to 4.22$)$ \\
\hline
\end{tabular}

modified after adjusting for smoking. The onset of their asthma, according to the questionnaire, was similar in cases and controls (asthma started less than nine years earlier - that is, during the epidemics - in $40.3 \%$ of cases and $46.3 \%$ in controls; $p>0.05)$. Considering the symptoms of lifetime asthma, the epidemic cases had fewer symptoms than controls. These differences were statistically significant for wheeze (odds ratio $=0.49,95 \%$ CI 0.33 to $0.81)$ and attacks of shortness of breath $(0 \cdot 28$, $95 \%$ CI $0 \cdot 11$ to $0 \cdot 71$ ).

Patients with epidemic asthma were more atopic than controls $(77.9 \% v 63.5 \% ; \mathrm{p}<0.01)$ in all age groups and in both sexes; no differences were found in reactions to the various types of allergens (table 2). The geometric mean of total IgE was higher in the patients with epidemic asthma $(144.2 \mathrm{IU} v 90.0 \mathrm{IU} ; \mathrm{p}<0.001)$ and this difference appeared in all age groups in men, although it was found only in older women (fig 1). After adjusting for smoking the differences for skin reactivity to any allergen changed from $2 \cdot 62$ to $2 \cdot 75$, whereas for specific allergens no changes occurred.

Baseline spirometric values were similar for cases and controls. The mean (SD) $\mathrm{FEV}_{1}$ (\% predicted) was $70(24 \cdot 7)$ in the cases and 69.6 $(25.4)$ in controls, and the FVC was $84.5(19 \cdot 2)$ and $86.5(18.9)$, respectively. No differences were found between the two groups when baseline $\mathrm{FEV}_{1}$ values were stratified according to age, sex, and smoking habit.

Of the 288 subjects in whom baseline spirometric tests were performed, 50 were excluded from the methacholine inhalation test because baseline $\mathrm{FEV}_{1}$ was less than $40 \%$ of predicted, 13 declined to participate, and five did not complete the test. In eight cases and 11 controls the baseline $\mathrm{FEV}_{1}$ fell $>20 \%$ after saline administration. The percentage of subjects who

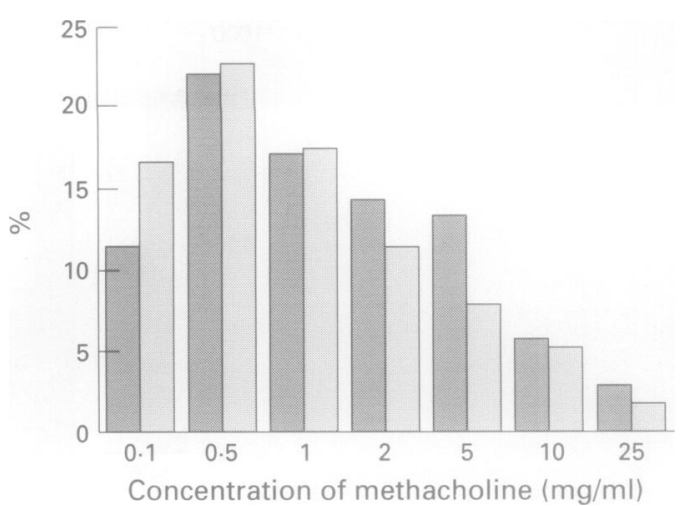

Figure 2 Results of methacholine bronchial challenge test in patients with epidemic (left hand columns) and nonepidemic asthma.

showed a fall $\leqslant 20 \%$ of baseline $\mathrm{FEV}_{1}$ at each dose of methacholine was similar in all groups (fig 2). The prevalence of bronchial hyperreactivity $\left(\mathrm{PC}_{20} \leqslant 25 \mathrm{mg} / \mathrm{ml}\right)$ was $94.5 \%$ in the cases and $92 \cdot 2 \%$ in controls $(58 \cdot 1 \%$ of cases and $66.1 \%$ of controls had a severe hyperreactivity $\left[\mathrm{PC}_{20} \leqslant 1 \mathrm{mg} / \mathrm{ml}\right], \mathrm{p}=\mathrm{NS}$ ). In the group of 50 patients in whom the methacholine inhalation test could not be performed, a bronchodilator test was administered to 39 subjects: baseline $\mathrm{FEV}_{1}$ increased by $15 \%$ or more in $12(52 \cdot 2 \%)$ cases and in $16(56 \cdot 2 \%)$ controls.

No differences were found in the types of medication taken at the time of the study except for inhaled corticosteroids which were taken by fewer of the patients with epidemic asthma $(34.3 \%$ v $49.0 \% ; \mathrm{p}<0.01)$ (table 3). Patients with epidemic asthma also took medication and underwent medical follow up less frequently than did patients with non-epidemic asthma.

Logistic regression analysis (table 4 ) showed that the previously described differences between cases and controls in age, smoking history, symptoms of asthma, atopy, and taking inhaled corticosteroids persisted after simultaneous adjustment.

\section{Discussion}

In a previous paper aimed at identifying risk factors of epidemic soybean asthma apart from soybean dust inhalation, we found that patients with epidemic asthma were older, more likely to be male, and more skin reactive to common aeroallergens. ${ }^{12}$ The male predominance was partially explained by the smoking habit which also appeared to constitute a risk factor. These characteristics have been reported in the New Orleans asthma epidemics, although the specific causative factor was not established..$^{13}$ In the present study we assessed possible differences in clinical, functional, and immunological characteristics between patients with epidemic and non-epidemic asthma.

Compared with controls, the patients with epidemic asthma had fewer symptoms of asthma during the previous year, had been admitted to emergency departments for asthma in the previous year on fewer occasions, and had needed treatment with inhaled steroids less frequently. The degree of bronchial obstruction 
and the response to methacholine were almost identical in the epidemic and non-epidemic asthmatic patients. Although severity of asthma is hard to define, it is normally evaluated by the frequency of exacerbations, the presence of night time symptoms, the need for daily medication, the duration of the disease, and the presence of chronic airways obstruction. ${ }^{14}$ Based on these criteria, our results indicate that the patients who had suffered as a result of the epidemics, studied two years later, had less severe asthma than the control group.

It is possible that the characteristics of the patients with epidemic asthma would have remained unchanged if the epidemic had not occurred or, possibly, that their asthma is still influenced by the residual effect of their exposure to soybean during the epidemics. Although Platts-Mills and colleagues ${ }^{1516}$ showed that avoiding contact with the allergen led to an improvement in clinical and bronchial hyperreactivity, several follow up studies of occupational asthma have shown that these abnormalities persist after the elimination or reduction of exposure to various agents including "red cedar"17 and toluene diisocyanate. ${ }^{18}$ It is possible, therefore, that the state of the patients previously affected by the epidemics may still be a consequence of the soybean allergen or a residual influence as low levels of soybean still exist in Barcelona. ${ }^{7}$

The observation of a type of asthma in the epidemic patients quite similar to that in the non-epidemic patients suggests that circumstances of exposure are a relevant determinant of sudden and life threatening asthma. Picado ${ }^{19}$ suggested that the small size of soybean particles might have facilitated their deposition deeper within the lung, provoking an unusually severe form of asthma. Another hypothesis could be related to the allergenic activity of the molecule. The main allergens implicated in the Barcelona epidemics have only been partially characterised and we cannot establish their allergenic potential. ${ }^{2021}$ Another possibility is that the dose of allergen is also a relevant factor in triggering a sudden severe attack of asthma.

Our results suggest that, two years after the elimination of the epidemics, those people affected had a favourable prognosis. This cor trasts with a higher risk of life threatening asthma and death during the epidemics. This paradox could be the result of a complex interaction between host and exposure. Host conditions and, in particular, a higher prevalence of atopy, made people more susceptible to sensitisation by soybean dust and to the development of soybean asthma. We suggest that the circumstances of exposure or the nature of the allergen might have been responsible for the unusual severity of the attacks of soybean epidemic asthma.

The authors wish to thank Professor Ann E Tattersfield for scientific advice, and Dr Marta Pulido for editorial assistance and copy editing.

This study was supported by a grant (no. 89/0924-3) from "Fondo de Investigación Sanitaria de la Seguridad Social", Madrid, Spain.

1 Benatar SR. Fatal asthma. $N$ Engl f Med 1986;314:423-9.

2 Wasserfallen JB, Schaller MD, Feihl F, Perret CH. Sudden asphyxic asthma: a distinct entity? Am Rev Respir Dis 1990;142:108-1.

3 O'Hollaren MT, Junginger JW, Offord KP, Somers MJ, O'Connell EJ, Ballard DJ, et al. Exposure to an aeroallergen as a possible precipitating factor in respiratory allergen as a possible precipitating factor in respiratory 324:359-63.

4 Antó JM, Sunyer J, Rodriguez-Roisin R, Suárez-Cervera M, Vásquez L, and the Toxicoepidemiological Committee. Community outbreaks of asthma associated with inhalation of soybean dust. $N$ Engl f Med 1989;320:1097102 .

5 Sunyer J, Antó JM, Rodrigo MJ, Morell F, and the Clinical Toxicoepidemiological Committee. Case-control study of serum immunoglobulin-E antibodies reactive with soybean epidemic asthma. Lancet 1989; i: 179-82.

6 Ferrer A, Torres A, Rodriguez Roisin, Roca J, Sunyer J, Ferrer A, Torres A, Rodriguez Roisin, Roca J, Sunyer J,
Antó JM. Characteristics of patients with soybean dustAnto JM. Characteristics of patients with soybean dust-
induced acute severe asthma requiring mechanical ventinduced acute severe asthma requirin
ilation. Eur Respir $\mathcal{F}$ 1990;3:429-33.

7 Antó JM, Sunyer J, Reed CE, Sabrià J, Martínez F, Morell $\mathrm{F}$, et al. Preventing asthma epidemics due to soybean by dust-control measures. $N$ Engl f Med 1993;329:1760-3.

8 Antó JM, Sunyer J. Epidemiologic studies of asthma epidemics in Barcelona. Chest 1990;98:185s-90s.

9 Ferris BG. Epidemiology standardization project II. Recommended respiratory disease questionnaire for use with adults and children in epidemiologic research. $A m R e$. Respir Dis 1978;118(Suppl):7-53.

10 Burney PGJ, Chinn S. Developing a new questionnaire for measuring the prevalence and distribution of asthma. Chest measuring the prevalence and
$1987 ; 91$ (Suppl 6):79s-83s.

11 Roca J, Sanchis A, Agusti-Vidal A, Segarra F, Navajas D, Rodriguez-Roisin R, et al. Spirometric reference values from a Mediterranean population. Bull Eur Physiopathol Respir 1986;22:217-24.

12 Sunyer J, Antó JM, Sabrià J, Rodrigo MJ, Roca J, Morell $\mathrm{F}$, et al. Risk factors of soybean epidemic asthma: the role of smoking and atopy. Am Rev Respir Dis 1992;145: 1096-102.

13 Salvaggio JE, Klein RC. New Orleans asthma I. Characterization of individuals involved in epidemics. $\mathcal{F}$ Allergy 1967;39:227-34.

14 Lenfant C. International asthma report. Eur Respir 7 1922; 5:601-4i.

15 Platts-Mills TAE, Tovey ER, Mitchell EB, Moszoro H, Nock P, Wilkins SR. Reduction of bronchial hyperreactivity during prolonged allergen avoidance. Lancer 1982;ii:675-7.

16 Platts-Mills TAE, Chapman, Pollart S, Luczynska CM, Ward GW. Specific allergens evoking immune reactions in the lung: relationship to asthma. Eur Respir f 1991;4 $68 \mathrm{~s}-77 \mathrm{~s}$.

17 Chan-Yeung M, Lam S, Koener S. Clinical features and natural history of occupational asthma due to western red cedar (Thuja plicata). Am $\mathcal{F}$ Med 1982;72:411-5.

18 Paggiaro PL, Loi AM, Rossi O, Ferrante B, Pardi F, Roselli $\mathrm{MG}$, et al. Follow-up study of patients with respiratory disease due to toluene diisocyanate (TDI). Clin Allergy disease due to

19 Picado C. Barcelona's asthma epidemics: clinical aspects and intriguing findings. Thorax 1992;47:197-200.

20 Rodrigo MJ, Morell F, Helm RM, Swanson M, Antó JM, Sinyer J. Identification and partial characterization of the suybean-dust allergens involved in the Barcelona asthma epidemics. $\mathcal{F}$ Allergy Clin Immunol 1990;85:778-84

21 González R, Pozo F, Zapatero L, Caravaca F, Carreira J. Purification and characterization major inhalant allergens from soybean hulls. Clin Exp Allergy 1992;22:748-55. 